Molecules 2003, 8, 608-613

molecules

ISSN 1420-3049

http://www.mdpi.org

\title{
A Facile Procedure for the Generation of Dichlorocarbene from the Reaction of Carbon Tetrachloride and Magnesium using Ultrasonic Irradiation
}

Haixia Lin *, Mingfa Yang, Peigang Huang and Weiguo Cao

Department of Chemistry, Shanghai University, Shanghai, 200436, P.R. China

*Author to whom correspondence should be addressed: e-mail linhaixia@ online.sh.cn

Received: 7 April 2003; in revised form: 7 July 2003 / Accepted: 20 July 2003 / Published: 31 July 2003

Abstract: An improved method for the generation of dichlorocarbene was developed that utilizes ultrasound in the reaction of carbon tetrachloride with magnesium. High yields of gem-dichlorocyclopropane derivatives can be obtained in the presence of olefins by this method.

Keywords: Dichlorocarbene; gem-dichlorocyclopropanes; ultrasonic irradiation; olefin addition; magnesium

\section{Introduction}

Gem-dichlorocyclopropanes are valuable intermediates in organic synthesis [1,2]. They are typically prepared by the addition of dichlorocarbene to olefins under phase-transfer catalysis conditions [3-5]. Sonochemical generation of dichlorocarbene has also been reported [6-8]. The reactions of dichlorocarbene with olefins in solid-liquid two-phase systems using ultrasonication usually afford high yields of double-bond addition products. In addition, excellent yields of diadducts have been obtained from dienes and dichlorocarbene under ultrasonication and phase-transfer catalyst [9]. 
Previously, we reported a novel route for the generation of dichlorocarbene by the reaction of carbon tetrachloride with magnesium in a neutral medium and hypothesized that the mechanism of these reactions might involve a single electron transfer [10]. However, these reactions suffered from several experimental drawbacks: some of the major ones being the sudden exotherm that occurs after an unpredictable induction period, foaming, and in some cases, the use of iodine as the activating agent. Sonication is able to effect reactions proceeding through radicals, and ultrasound has also provided a distinct alternative to the initiation and enhancement of synthetic reactions involving metals as a reagent [11]. This encouraged us to react carbon tetrachloride and magnesium under the new conditions in order to eliminate above drawbacks. Our method is based on the action of ultrasound on carbon tetrachloride and magnesium systems (Scheme 1). Dichlorocarbene formed in this manner adds readily to alkenes, affording excellent yields of corresponding dichlorocyclopropanes. The results are presented in Table 1.

\section{Scheme 1}

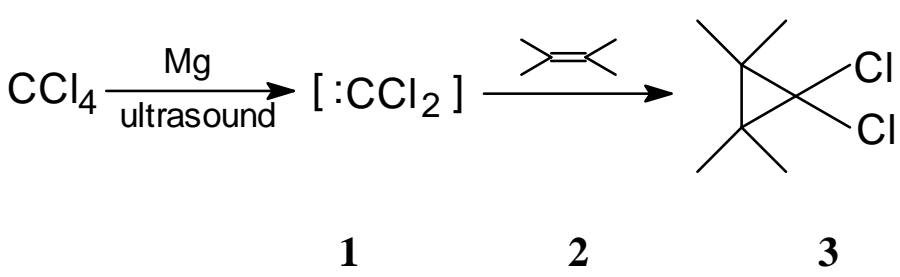

\section{Results and Discussion}

The influence of solvents on the reaction course was studied. In principle, many organic solvents can be used. The effects of varying solvents on the rates of the reactions and yields of products are well documented in the literature $[10,12,13]$. It was shown previously that higher yields of products 3 were obtained in ethyl ether than in a mixture solvent of ethyl ether and tetrahydrofuran in the absence of sonication [10]. However, in the former case complete reaction was achieved only after $12 \mathrm{~h}$, whereas in the latter, complete reaction could be achieved in $4 \mathrm{~h}$. In contrast, under the influence of sonication, using a 4:1 mixture of ethyl ether and tetrahydrofuran as the solvent, yields and reaction times compare favorably with the use of ethyl ether as the solvent. In summary, ethyl ether is a preferred solvent for the conventional reaction, while the most efficient solvent for the sonicated reaction is the 4:1mixture of ethyl ether and tetrahydrofuran. Sonication also eliminates delayed exotherm, and this may contribute to the improved performance of the reaction in the 4:1 mixture of ethyl ether and tetrahydrofuran in an ultrasonication case. The reaction occurred immediately in anhydrous tetrahydrofuran under ultrasonic irradiation, but it was difficult to control. In addition, the effect of amount of water in ether on the induction time was observed. There was induction time of 5-15 min. using THF as solvent that was only distilled from $\mathrm{KOH}$. An increase in the water content of the ether resulted in an increase in the induction time and a decrease in the yields of the products. Therefore, all of the reagents must be dry to facilitate reaction between carbon tetrachloride and magnesium in an ether solvents using ultrasound. 
Table 1. Gem-dichlorocyclopropane Derivatives Prepared using Ultrasonic Irradiation

\begin{tabular}{|c|c|c|c|c|c|}
\hline \multirow{2}{*}{ Entry } & \multirow{2}{*}{$\begin{array}{c}\text { Olefin } \\
\mathbf{2} \\
\end{array}$} & \multirow{2}{*}{$\begin{array}{c}\text { Product } \\
\mathbf{3}\end{array}$} & \multirow{2}{*}{$\begin{array}{c}\text { B.P. }\left({ }^{\circ} \mathrm{C} / \mathrm{Pa}\right) \\
\text { or M.P. }\left({ }^{\circ} \mathrm{C}\right)\end{array}$} & \multicolumn{2}{|c|}{ Yield (\%) } \\
\hline & & & & A & $\mathrm{B}[10]]$ \\
\hline & & & $64-66 / 800$ & 92 & 88 \\
\hline $\mathrm{b}$ & & & $45-47 / 133$ & 95 & 93 \\
\hline $\mathrm{c}$ & & & $82-84 / 133$ & 93 & 87 \\
\hline d & & & 66-67(m.p.) & 85 & 72 \\
\hline e & & & $\mathrm{C}$ & 61 & 40 \\
\hline & & & $107-109 / 133$ & 77 & 59 \\
\hline & & & $57-59 / 933$ & 91 & 85 \\
\hline & & & 167-169(m.p.) & 75 & 56 \\
\hline 1 & & & $110-112 / 267$ & 78 & 63 \\
\hline $\mathrm{j}^{\mathrm{D}}$ & & & $123-126 / 667$ & 81 & 61 \\
\hline $\mathbf{\Lambda}$ & & & $67-69 / 933$ & 76 & 68 \\
\hline
\end{tabular}

Notes: (A) Ultrasonic irradiation reaction conditions; (B) literature yields based on reflux reaction conditions (solvent: ethyl ether, $12 \mathrm{~h}$ ); (C) the pure product obtained by VLC is an oily liquid; (D) $\mathrm{CCl}_{4}: \mathrm{Mg}:$ diolefin $=4: 2: 1$ (molar ratio); $2: 1: 1$ in other reactions. 
In order to enhance the yields of gem-dichlorocyclopropane derivatives, it is necessary to control the molar ratios of the reactants. Compared to other molar ratios of reactants examined, a 2:1:1 carbon tetrachloride - magnesium - olefin ratio consistently produced higher yields. The reaction was completed in 45-60 min under ultrasound.

The main advantage of this method is that the reaction carried out in a neutral medium, so some side reactions caused by the strong base in phase transfer catalyst system can be avoided. For example, when there is an ester group (entry e) or a carbonyl group (entry f) in the olefin molecule, no saponification and aldol condensation take place and no Grignard reaction products are formed either. For diolefins which have different steric hindrance at the double bonds, good addition selectivity can be observed (entry c). For symmetrical diolefins, the diadduct was the major product with a molar ratio $\mathrm{CCl}_{4}$-Mg-di-olefin of 4:2:1(entries $\mathrm{h}$ and $\mathrm{j}$ ), but with a molar ratio of 2:1:1 and the same reaction conditions the monoadduct was formed almost exclusively (entries $\mathrm{i}$ and $\mathrm{k}$ ), while for olefins with a bridging bond, additional products will not arise from rearrangement (entry d). It is thus clear that a wide range of structurally varied olefins by the procedure provide gem-dichlorocyclopropane derivatives in good yields. Moreover, our approach requires only relatively short reaction times and provides better yields, no chemical activation of $\mathrm{Mg}$ is needed, no delayed exotherm is observed, the reaction proceeds smoothly and the reaction time and yield are reproducible. Studies on the mechanism of the reaction under ultrasound and the reactions of carbon tetrachloride and magnesium with electrophilic alkenes are currently underway.

\section{Experimental}

\section{General}

Gas chromatography (GC) was performed on a Shimadzu 14B chromatographic instrument. IR spectra were recorded with a Nicolet AVATAR FT-IR-360 spectrometer. ${ }^{1} \mathrm{H}-\mathrm{NMR}$ were obtained for $\mathrm{CCl}_{4}$ solutions on a JEOL JNM-PMX $60 \mathrm{Si}$ spectrometer. Elemental analysis data were taken on a Perkin-Elmer 240C elemental analytical instrument. Melting points determined on a XT 4A melting point apparatus. Ultrasound was produced with SB-3200 ultrasonic cleaner.

\section{General Synthetic Procedure}

A mixture of magnesium powder $(25 \mathrm{mmol})$, olefin $(25 \mathrm{mmol})$ and carbon tetrachloride $(50 \mathrm{mmol})$ in anhydrous ethyl ether $(16 \mathrm{~mL})$ and anhydrous tetrahydrofuran $(4 \mathrm{~mL})$ was placed in a flask. The flask was immersed in the water bath of an ultrasonic cleaner, positioned ca. $0.5 \mathrm{~cm}$ above the bottom of and the level of water was adjusted to that of the solvent level inside the flask. The mixture was then treated with ultrasonic irradiation at room temperature until all magnesium was consumed, and then for an additional $5 \mathrm{~min}$. To the mixture was then added $10 \% \mathrm{NH}_{4} \mathrm{Cl}$ solution $(15 \mathrm{~mL})$ and the aqueous layer was extracted with ethyl ether $(3 \times 8 \mathrm{~mL})$. The combined organic layers were dried over anhydrous 
sodium sulfate. The solvent was evaporated and the residue was distilled under vacuum or purified using vacuum liquid chromatography (VLC). The physical and spectral properties of products were found to be identical to those reported in the literature.

7,7-dichlorobicyclo[4.1.0] heptane (3a): IR: 2940, 750, $735 \mathrm{~cm}^{-1} ;{ }^{1} \mathrm{H}-\mathrm{NMR}: 1.0-1.3$ (m, 4H), 1.5-1.8 (m, 6H); Anal. Calcd for $\mathrm{C}_{7} \mathrm{H}_{10} \mathrm{Cl}_{2}$ : C, 50.94; H, 6.11. Found: C, 50.97; H, 6.13.

7,7-dichloro-2-oxabicyclo[4.1.0] heptane (3b): IR: 2960, 2930, 1100, 730, $710 \mathrm{~cm}^{-1}$; ${ }^{1} \mathrm{H}-\mathrm{NMR}: 1.1-1.9$ (m, 5H), 3.1-3.9 (m, 3H); Anal. Calcd for $\mathrm{C}_{6} \mathrm{H}_{8} \mathrm{Cl}_{2} \mathrm{O}$ : C, 43.15; H, 4.83. Found: C, 43.18; H, 4.81.

4,4'-dichloroquadricyclo[6.2.1. $\left.0^{2,7} \cdot 0^{3,5}\right]$ undec-9-ene (3c): IR: 3020, 1620, 1575, $720 \mathrm{~cm}^{-1}$; ${ }^{1} \mathrm{H}-\mathrm{NMR}$ : 1.0-1.4 (m, 4H), 1.5-1.9 (m, 4H), 2.0-2.6 (m, 2H), 5.0-5.4 (m, 2H); Anal. Calcd for $\mathrm{C}_{11} \mathrm{H}_{12} \mathrm{Cl}_{2}$ : C, 61.42; H, 5.62. Found: C, 61.38; H, 5.60.

2,8.8-trimethyl-3,3-dichlorotricyclo[4.1.1.0 $0^{2,4}$ ]octane (3d): IR: 2950, 2935, 1385, 750, $720 \mathrm{~cm}^{-1}$; ${ }^{1} \mathrm{H}-\mathrm{NMR}: 0.9-1.2(\mathrm{~m}, 3 \mathrm{H}), 1.2(\mathrm{~s}, 9 \mathrm{H}), 1.3-1.5(\mathrm{~m}, 4 \mathrm{H})$; Anal. Calcd for $\mathrm{C}_{11} \mathrm{H}_{16} \mathrm{Cl}_{2}$ : C, 60.29; H, 7.36. Found: C, 60.32; H, 7.38.

1,1-dichloro-2-(w-ethyl nonanatyl)cyclopropane (3e): IR: 3015, 2950, 2925, 1750, 1250, 740, $710 \mathrm{~cm}^{-1}$; ${ }^{1} \mathrm{H}-\mathrm{NMR}: 1.0-1.3(\mathrm{~m}, 5 \mathrm{H}), 1.4-2.4(\mathrm{~m}, 15 \mathrm{H}), 2.7-2.8(\mathrm{t}, 2 \mathrm{H}), 3.6-3.9(\mathrm{q}, 2 \mathrm{H})$. Anal. Calcd for $\mathrm{C}_{14} \mathrm{H}_{24} \mathrm{Cl}_{2} \mathrm{O}_{2}$ : C, 56.95; H, 8.19. Found: C, 56.98; H, 8.21.

1,1-dichloro-2,2-dimethyl-3-(3-butanonylcyclopropane (3f): IR: 2950, 1710, 730, $710 \mathrm{~cm}^{-1}$; ${ }^{1} \mathrm{H}-\mathrm{NMR}$ : 1.0-1.3 (m, 9H), 2.6-2.9 (m, 5H); Anal. Calcd for $\mathrm{C}_{9} \mathrm{H}_{14} \mathrm{Cl}_{2} \mathrm{O}$ : C, 51.69; H, 6.75. Found: C, 51.63; H, 6.71 .

1,1-dichloro-2-pentylcyclopropane (3g): IR: 3010, 2950, 2925, 740, $710 \mathrm{~cm}^{-1}$; ${ }^{1} \mathrm{H}-\mathrm{NMR}$ : 0.9-1.1 (m, $3 \mathrm{H}), 1.2-1.7$ (m, 11H); Anal. Calcd for $\mathrm{C}_{8} \mathrm{H}_{14} \mathrm{Cl}_{2}$ : C, 53.06; H, 7.79. Found: C, 53.10; H, 7.82.

5,5,10,10-tetrachlorotricyclo[7.1.0.0 $0^{4,6}$ ]decane (3h): IR: 3010, 2900, 770, $720 \mathrm{~cm}^{-1}$; ${ }^{1} \mathrm{H}-\mathrm{NMR}: 1.1-1.6$ (m, 8H), 1.8-2.1 (m, 4H); Anal. Calcd for $\mathrm{C}_{10} \mathrm{H}_{12} \mathrm{Cl}_{4}$ : C, 43.83; H, 4.41. Found: C, 43.72; H, 4.43.

9,9-dichlorobicyclo[6.1.0]-4-nonylene (3i): IR: 3010, 1645, 755, $730 \mathrm{~cm}^{-1}$; ${ }^{1} \mathrm{H}-\mathrm{NMR}: 1.3-1.9$ (m, 4H), 1.9-2.6 (m, $6 \mathrm{H}), 5.4(\mathrm{~S}, 2 \mathrm{H})$; Anal. Calcd for $\mathrm{C}_{9} \mathrm{H}_{12} \mathrm{Cl}_{2}$ : C, 56.56; H, 6.33. Found: C, 56.78; H, 6.35.

1,4-bis(2,2-dichlorocyclopropyl)butane (3j): IR: 2920, 2860, 1125, $745 \mathrm{~cm}^{-1}$; ${ }^{1} \mathrm{H}-\mathrm{NMR}: 1.0-1.6$ (m, 14H); Anal. Calcd for $\mathrm{C}_{10} \mathrm{H}_{14} \mathrm{Cl}_{4}$ : C, 43.51; H, 5.11. Found: C, 43.34; H, 5.13. 
1,1-dichloro-2-(5-hexylenyl)cyclopropane (3k): IR: 3055, 2920, 2850, 1640, 1115, 910, $745 \mathrm{~cm}^{-1}$;

${ }^{1} \mathrm{H}$ - NMR: 1.0-2.0 (m, $\left.11 \mathrm{H}\right)$, 4.5-5.3 and 5.8-6.2 (m, 3H); Anal. Calcd for $\mathrm{C}_{9} \mathrm{H}_{14} \mathrm{Cl}_{2}$ : C, 55.98; H, 7.31. Found: C, 56.19; H, 7.28.

\section{References}

1. Kirmse, W. Carbene Chemistry; Academic Press: New York, London, 1971.

2. Magarian, R. A.; Pento, J.T.; Griffin, M. T. U. S. Pat. US 5397802 A 1995, 22.

3. Makosza, M. Tetrahedron Lett., 1969, 4659.

4. Nomura, E.; Taniguchi, H.; Otsuji, Y. Bull. Chem. Soc. Jpn., 1994, 67, 792.

5. Jayachandran, J. P.; Wang, M. L. Appl. Catal. A-Gen., 2001, 206, 19.

6. Regen, S. L.; Singh, A. J. Org. Chem.; 1982, 47, 1587.

7. Xu, L.; Smith, W. B.; Brinker, U. H. J. Am. Chem. Soc.; 1992, 114, 783

8. Xu, L.; Tao, F.; Yu, T. Acta Chim. Sinica, Chin. Ed.; 1988, 46, 340.

9. Didriksen, T.; Skattebøl, L. Synth. Commun., 1999, 29, 1087.

10. Lin, H. X.; Xu, L. H.; Huang, N. J. Chem. J. Chin. Univer., 1995, 16, 1572.

11. Mason, T. J. Chem. Soc. Rev., 1997, 26, 443.

12. Fedorynski, M. Tetrahedron, 1999, 55, 6329.

13. Xu, L.; Tao, F.; Yu, T. Acta Chim. Sinica, Chin. Ed. 1986, 44, 1134.

Sample Availability: Available from the authors.

(C) 2003 by MDPI (http://www.mdpi.org). Reproduction is permitted for noncommercial purposes. 